\title{
Electrochemical Detection of Sequence-Specific DNA with the Amplification of Gold Nanoparticles
}

\author{
Yuzhong Zhang, Zhen Wang, Yuehong Wang, Lei Huang, Wei Jiang, and Mingzhu Wang \\ College of Chemistry and Materials Science, Anhui Key Laboratory of Chemo-Biosensing, Anhui Normal University, \\ Wuhu 241000, China \\ Correspondence should be addressed to Yuzhong Zhang, zhyz65@mail.ahnu.edu.cn
}

Received 6 December 2010; Accepted 28 March 2011

Academic Editor: Farnoush Faridbod

Copyright ( 2011 Yuzhong Zhang et al. This is an open access article distributed under the Creative Commons Attribution License, which permits unrestricted use, distribution, and reproduction in any medium, provided the original work is properly cited.

\begin{abstract}
A sensitive electrochemical DNA biosensor was prepared based on mercaptoacetic acid (MAA)/gold nanoparticles (AuNPs) modified electrode. Probe DNA ( $\mathrm{NH}_{2}$-DNA) was covalently linked to the carboxyl group of MAA in the presence of 1-ethyl-3-(3dimethylaminopropyl) carbodiimide hydrochloride (EDC) and N-hydroxyl-succinimide (NHS). Scanning electron microscopy (SEM) and electrochemical impedance spectra (EIS) were used to investigate the film assembly process. The DNA hybridization events were monitored by differential pulse voltammetry (DPV), and adriamycin was used as the electrochemical indicator. Also the factors influencing the performance of the DNA hybridization were investigated in detail. Under the optimal conditions, the signal was linearly changed with target DNA concentration increased from $5.0 \times 10^{-13}$ to $1.0 \times 10^{-9} \mathrm{M}$ and had a detection limit of $1.7 \times 10^{-13} \mathrm{M}$ (signal/noise ratio of 3 ). In addition, the DNA biosensor showed good reproducibility and stability during DNA assay.
\end{abstract}

\section{Introduction}

Nowadays, specific sequences DNA detection has become a most important research field due to its application in disease diagnosis, drug screening, epidemic prevention, and environmental protection [1-3]. Many methods have been used for DNA detection including optics $[4,5]$, piezoelectricity [6], surface plasmon resonance spectroscopy [7], and electrochemistry [8-11]. Among them, it should be noted that electrochemical DNA sensor is a promising candidate because of its simple, rapid, inexpensive, high sensitivity and selectivity.

AuNPs are well-known low-dimensional functional materials with large surface-to-volume ratios and biocompatibility with biosystem. So it is often used for DNA biosensor material. Zhang et al. [12] and Zhang et al. [13, 14] have fabricated some AuNPs-based electrochemical DNA sensors. Wang and his coworkers have invented a DNA biosensor based on amplified voltammetric detection of DNA hybridization via oxidation of ferrocene caps on gold nanoparticle/streptavidin conjugates [15]. Abouzar and his coworkers have developed a label-free electrical detection of DNA hybridization functionalized with AuNPs [16]. Our groups have fabricated several DNA biosensor based on AuNPs amplification [17-19]. Castañeda et al. have a review on electrochemical sensing of DNA using AuNPs [20].

In the present paper, we fabricate an electrochemical DNA biosensor for detection of $\mathrm{E}$. coli sequence with the amplification of gold nanoparticles. AuNPs were firstly electrodeposited on the surface of the gold electrode. And the modified AuNPs were used to increase the electrode surface area for more binding amount of MAA so as to enhance the immobilization amount of probe DNA. DPV was used to monitor DNA hybridization event by measurement of the intercalated adriamycin. This DNA biosensor shows a higher sensitivity and selectivity. 


\section{Experiment}

2.1. Materials. Adriamycin, MAA, sodium dodecyl sulfate (SDS), EDC, and NHS were purchased from Alfa Aesar (Tianjing, China). $\mathrm{HAuCl}_{4} \cdot 4 \mathrm{H}_{2} \mathrm{O}$ was obtained from Shanghai Chemical Reagent Co., Ltd. Sodium hydroxide and Phosphate were obtained from Nanjing Chemical Reagent (Nanjing, China). Various oligonucleotides were purchased from Shanghai Sangon Bioengineering Technology \& Services Co., Ltd. (Shanghai, China). And their sequences are as follows.

Probe Sequence. 5'- $\mathrm{NH}_{2}$-GAG CGG CGC AAC ATT TCA GGT CGA-3'.

Complementary Sequence. 5'-TCG ACC TGA AAT GTT GCG CCG CTC-3'.

Noncomplementary Sequence. 5'-AGC TGG ACT TTA CAA CGC GGC GAG-3'.

Single-Base Mismatched Sequence. 5'-TCG ACC TGA AAC GTT GCG CCG CTC-3'.

Stock solutions of oligonucleotides were prepared with $0.01 \mathrm{M}$ phosphate buffer solution (PBS, pH 7.40) and stored in a freezer. The following buffer solutions were used: hybridization buffer solution $(0.1 \mathrm{M} \mathrm{NaCl}+0.01 \mathrm{M}$ PBS, $\mathrm{pH} 7.40)$ and electrochemical test solution (0.01 M PBS, $\mathrm{pH}$ 7.40). All chemicals were of analytical grade and used without further purification. All solutions were prepared with twice-quartz-distilled water.

2.2. Apparatus. All electrochemical measurements such as electrochemical impedance spectroscopy (EIS), cyclic voltammetry $(\mathrm{CV})$, and DPV were performed on a CHI 660A electrochemical workstation (Shanghai Chenhua Instruments Co., China). The three-electrode system was used in the experiment with bare gold electrode or modified electrode as working electrode, a saturated calomel electrode (SCE) as reference electrode and platinum wire as counter electrode. EIS was performed in $0.1 \mathrm{M} \mathrm{KCl}$ solution containing $5.0 \mathrm{mM} \mathrm{K}_{4} \mathrm{Fe}(\mathrm{CN})_{6} / \mathrm{K}_{3} \mathrm{Fe}(\mathrm{CN})_{6}(\mathrm{pH} 7.40)$ with the frequency range between 0.1 and $100 \mathrm{kHz}$ at the formal potential of $0.115 \mathrm{~V}$. CV and DPV were carried out in a $10 \mathrm{~mL}$ electrochemical cell with $5 \mathrm{~mL}$ solutions, from which oxygen was removed by purging with high-purity nitrogen for $20 \mathrm{~min}$, and a blanket of nitrogen was maintained over the solution during the measurements. The morphology of AuNPs was obtained by scanning electron microscopy (SEM) using a JEOLJSM-6700F microscope (Hitachi, Japan).

\subsection{Preparation of ssDNA/MAA/AuNPs Modified Electrode.} Prior to modification, the bare gold electrode was firstly polished to a mirror-like surface with gamma alumina suspensions $(1.0 \mu \mathrm{m}, 0.25 \mu \mathrm{m}$ and $0.05 \mu \mathrm{m}$, resp.). Then it was rinsed with twice-quartz-distilled water and cleaned ultrasonically sequentially in water and $95 \%$ ethanol for $3 \mathrm{~min}$. Finally, the electrode was electrochemically cleaned between -0.3 and $+1.55 \mathrm{~V}$ in $0.5 \mathrm{M} \mathrm{H}_{2} \mathrm{SO}_{4}$ until a stable $\mathrm{CV}$ was obtained.
AuNPs electrochemical deposition was performed in 2.0 $\times 10^{-3} \mathrm{M} \mathrm{HAuCl}_{4} / 0.2 \mathrm{M} \mathrm{KNO}_{3}$ solution and electrodeposition time is $50 \mathrm{~s}$ at $-250 \mathrm{mV}$ (versus SCE). The electrode was denoted as AuNPs/Au. Then the AuNPs/Au electrode was immersed into a $10.0 \mathrm{mM}$ MAA for $4 \mathrm{~h}$ to form MAA film through $\mathrm{Au}-\mathrm{S}$ bond. The obtained electrode was denoted as MAA/AuNPs/Au.

After the MAA/AuNPs/Au modified electrode was immersed in a mixture of $5.0 \mathrm{mM}$ EDC and $8.0 \mathrm{mM}$ NHS $(\mathrm{pH} 7.40)$ for $45 \mathrm{~min}, 8 \mu \mathrm{L}$ of $1.0 \times 10^{-5} \mathrm{M}$ probe DNA was dropped on the surface of MAA/AuNPs/Au and kept it for $12 \mathrm{~h}$ at the room temperature. Finally, the probe modified electrode was immersed into $0.1 \%$ SDS solution for $10 \mathrm{~min}$ to remove the unbound probe DNA. Thus the probe DNA modified electrode was prepared, and it was denoted ssDNA/MAA/AuNPs/Au.

2.4. Hybridization and Electrochemical Detection. The hybridization experiment was carried out by immersing the probe modified electrode into hybridization buffer solution containing different concentrations of target DNA for 25 $\min$ at $37^{\circ} \mathrm{C}$. The hybridized electrode was then rinsed with PBS containing $0.1 \%$ SDS to remove the unhybridized target DNA. After that, it was incubated in $1.0 \times 10^{-6} \mathrm{M}$ adriamycin for $20 \mathrm{~min}$, followed by rinsing with water and $0.01 \mathrm{M}$ PBS for three times to remove physically absorbed adriamycin.

The DNA hybridization was assessed with the DPV peak current of intercalated adriamycin in pH 7.0 PBS, and the concentration of complementary DNA was quantified by peak current of adriamycin $(\Delta I)$, which was subtracted from the reduction peak current generated at the ssDNA/ MAA/AuNPs modified electrode $\left(\Delta I=I_{\mathrm{ds}-\mathrm{DNA}}-I_{\mathrm{ss}-\mathrm{DNA}}\right)$. DPV parameters were as follows: potential range: $-0.45 \sim$ $-0.80 \mathrm{~V}$; amplitude: $0.05 \mathrm{~V}$; pulse width: $0.05 \mathrm{~s}$; sample width: $0.0167 \mathrm{~s}$; pulse period: $0.2 \mathrm{~s}$; quiet time: $2 \mathrm{~s}$. The schematic diagram of the DNA biosensor fabrication and electrochemical detection is illustrated in Scheme 1.

\section{Results and Discussion}

3.1. Electrochemical Impedance Spectroscopy at Different Modified Electrode. Impedance spectroscopy is an effective method for probing the surface features of the modified electrode. In EIS, the semicircle part at higher frequencies corresponds to the electron transfer limited process or the electron transfer resistance $\left(R_{\mathrm{et}}\right)$. The linear sect at lower frequencies shows a controlled diffusion process. Figure $1 \mathrm{com}-$ pares the Nyquist plots of $5.0 \mathrm{mM} \mathrm{K} \mathrm{K}_{4} \mathrm{Fe}(\mathrm{CN})_{6} / \mathrm{K}_{3} \mathrm{Fe}(\mathrm{CN})_{6}$ at the different modified electrodes. When AuNPs were electrodeposited on the surface of the gold electrode (curve b), the $R_{\text {et }}$ was decreased in contrast to the bare gold electrode (curve a). The results could be rationalized by improved electron transfer kinetics of redox probe on AuNPs modified electrode. The assembly of MAA monolayer on electrode surface induced a larger $R_{\text {et }}$ (curve c) as compared with that of AuNPs electrode due to the electrostatic repulsion between the negative MAA and $\mathrm{K}_{4} \mathrm{Fe}(\mathrm{CN})_{6} / \mathrm{K}_{3} \mathrm{Fe}(\mathrm{CN})_{6}$. When the MAA/AuNPs/Au surface was activated with EDC and NHS, 

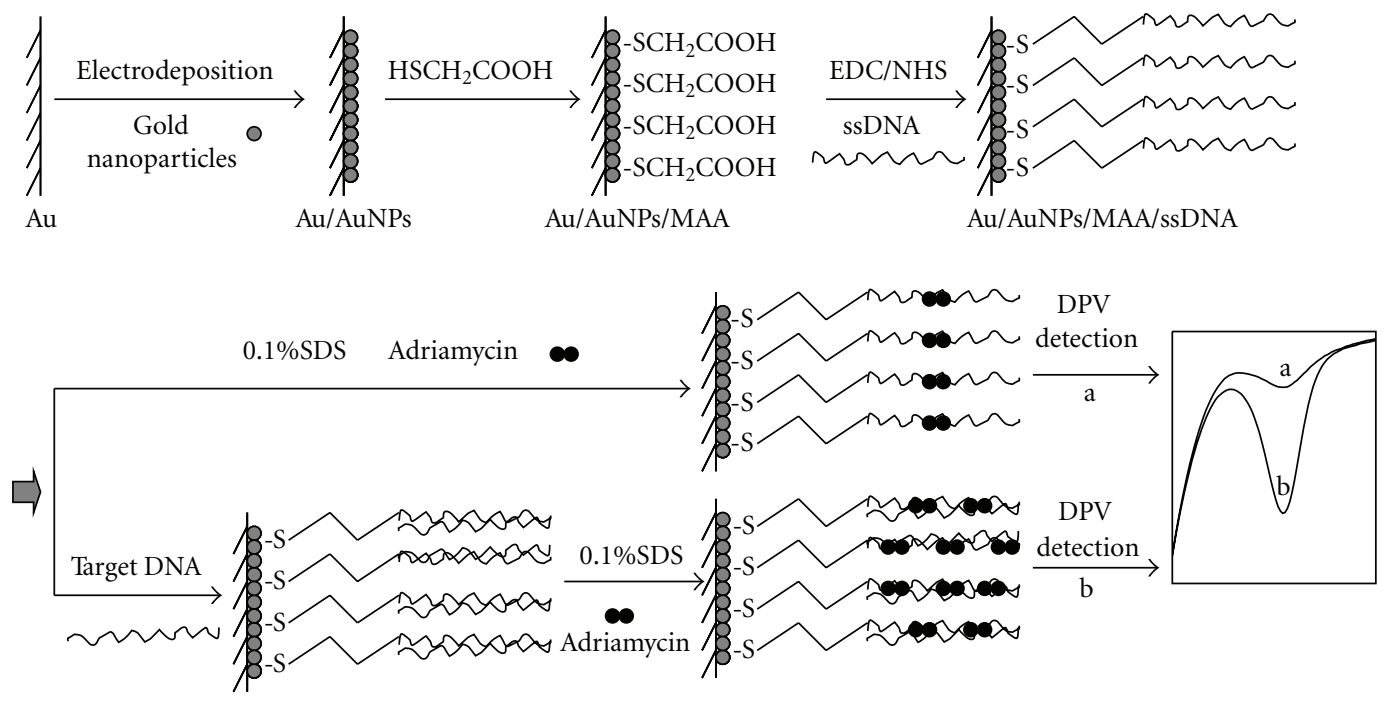

Scheme 1: The schematic diagram of the procedure available for DNA biosensor fabrication and electrochemical detection.

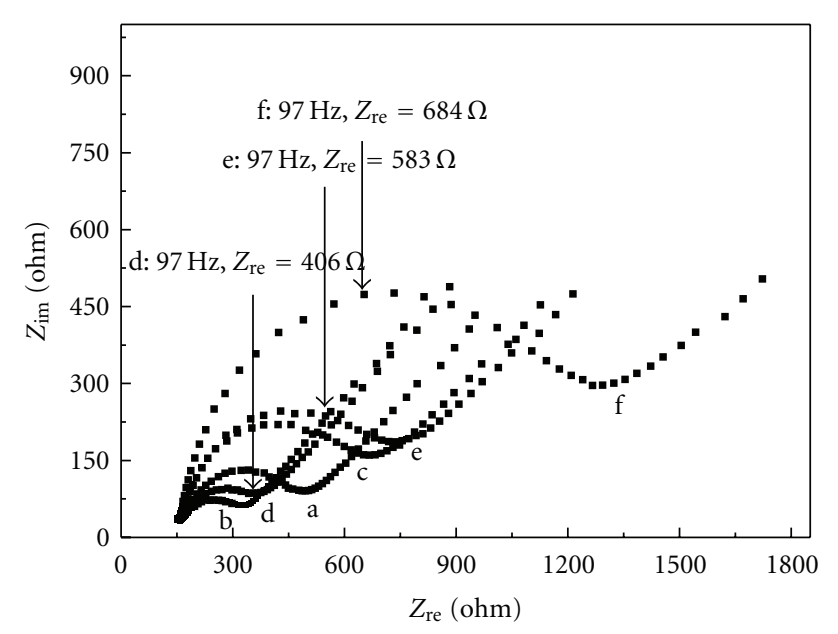

Figure 1: Nyquist plots obtained at different modified electrode. (a) Bare gold electrode, (b) AuNPs, (c) MAA/AuNPs, (d) activated MAA/AuNPs, (e) ss-DNA/MAA/AuNPs, and (f) ds-DNA/MAA/ AuNPs modified electrodes. The supporting electrolyte was $0.1 \mathrm{M}$ $\mathrm{KCl}$ solution containing $5.0 \mathrm{mM} \mathrm{K}_{4} \mathrm{Fe}(\mathrm{CN})_{6} / \mathrm{K}_{3} \mathrm{Fe}(\mathrm{CN})_{6}$.

the $R_{\text {et }}$ was evidently decreased because the content of carboxyl group was decreased (curve d). When the probe DNA was covalently immobilized on the electrode surface, the $R_{\text {et }}$ is obviously increased because of the strong electrostatic repulsion between the $\mathrm{K}_{4} \mathrm{Fe}(\mathrm{CN})_{6} / \mathrm{K}_{3} \mathrm{Fe}(\mathrm{CN})_{6}$ molecules and the negative-charged phosphate skeletons of DNA (curve e). After hybridization of the probe DNA with $1.0 \times$ $10^{-10} \mathrm{M}$ complementary ssDNA, $R_{\text {et }}$ was obviously increased (curve $\mathrm{f}$ ). Therefore, this impedance change indicated that modification and DNA hybridization successfully occurred on the electrode surface.

3.2. Optimization of DNA Assay Conditions. It is reported that the morphology, magnitude, and distribution of AuNPs could be controlled through controlling deposition time or $\mathrm{HAuCl}_{4}$ concentrations [21]. In order to obtain an optimization for DNA immobilization and hybridization, in this work, magnitude and distribution of AuNPs was performed by changing deposition time and keeping $\mathrm{HAuCl}_{4}$ concentrations a constant. Two different methods (SEM, DPV) were used to investigate the optimization of $\mathrm{Au}$ deposition time, respectively.

Figure 2(A) shows SEM images of AuNPs at different periods of deposition time. It can be observed that morphology and distribution of AuNPs was depended on deposition time. When deposition time was $50 \mathrm{~s}$, AuNPs are about $10 \mathrm{~nm}$ and have the same size (b), when the deposition time reached $110 \mathrm{~s}$, a large number of gold clusters were found and lead to a very rough surface (c). Therefore, $50 \mathrm{~s}$ was the suitable for AuNPs preparation from the views of uniform size, higher density, and good shape.

The characteristic of AuNPs at different deposition time was investigated by DPV using adriamycin as electroactive indicator. Figure 2(B) shows the plot of the peak currents of adriamycin dependence of deposition time. It could be observed that peak current increased as deposition time from 0 to $50 \mathrm{~s}$, and the peak current decreased slightly when the deposition time exceeded $50 \mathrm{~s}$. So $50 \mathrm{~s}$ was selected as the optimal deposition time.

The amount of probe DNA immobilization on the electrode surface is an important factor because the amount of probe DNA directly influences the sensitivity of a DNA biosensor [22]. Figure 3(a) shows the peak current of adriamycin before and after hybridization dependence of probe DNA amount. From Figure 3(a), we can observe the peak current of adriamycin gradually increased with the amount of probe DNA from 3 to $8 \mu \mathrm{L}$, and a slight decrease when the amount of probe DNA is over $8 \mu \mathrm{L}$. Thus, $8 \mu \mathrm{L}$ probe DNA was selected in our experiments.

The accumulation time of electrochemical indicator is another factor for sensitivity of DNA biosensor. Figure 3(b) 


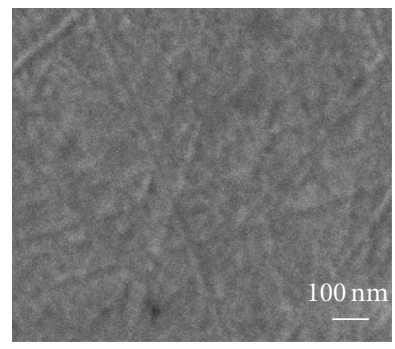

(a)

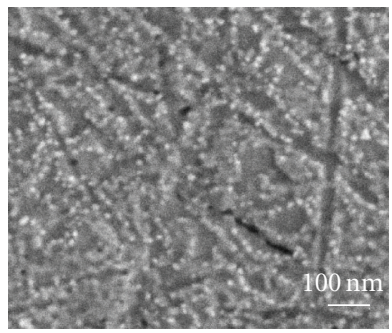

(b)
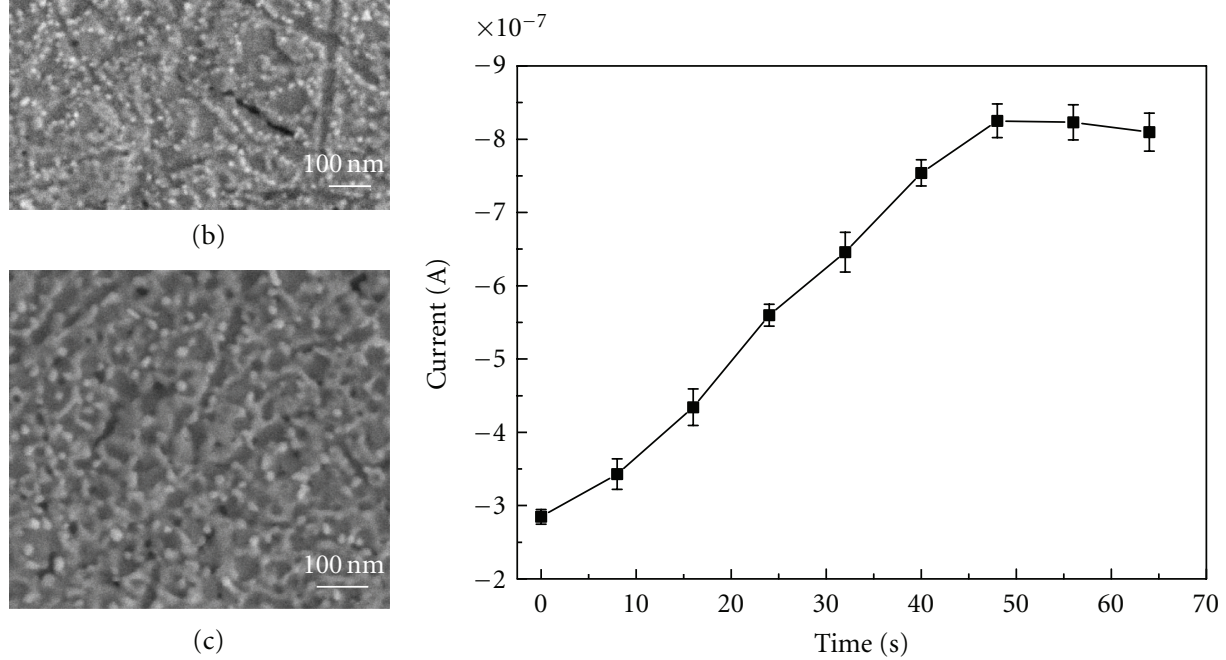

(A)

(B)

FIgURE 2: (A) SEM images of AuNPs at various deposition time. (a) 0, (b) $50 \mathrm{~s}$, (c) $110 \mathrm{~s}$, Deposition potential is $-250 \mathrm{mV}$ (versus SCE). (B) DPV responses of adriamycin dependence of deposition time. Electrochemical deposition was performed in $3.0 \mathrm{mM} \mathrm{HAuCl}_{4}$ at various times $(t=0,8,16,24,32,40,48,56$, and $64 \mathrm{~s})$. DPV measurement was performed in $0.01 \mathrm{M}$ PBS $(\mathrm{pH} 7.40)$ containing $1.0 \times 10^{-6} \mathrm{M}$ adriamycin. DPV parameters were as follows: potential range: $-0.45 \sim-0.80 \mathrm{~V}$; amplitude: $0.05 \mathrm{~V}$; pulse width: $0.05 \mathrm{~s}$; sample width: $0.0167 \mathrm{~s}$; pulse period: $0.2 \mathrm{~s}$; quiet time: $2 \mathrm{~s}$.

shows the reduction peak currents of adriamycin dependence of the accumulation time. It could be seen that the peak current increased significantly with the increasing accumulation time from 5 to $20 \mathrm{~min}$. When the accumulation time is higher than $20 \mathrm{~min}$, the peak current of adriamycin keeps constant relatively. Therefore, $20 \mathrm{~min}$ was selected as the optimum accumulation time.

Figure 3(c) shows the peak current of adriamycin dependence of the hybridization time. From Figure 3(c), it could be seen that the reduction peak currents of adriamycin increased significantly as the hybridization time increased from 5 to $25 \mathrm{~min}$ and keep constant after $25 \mathrm{~min}$. This indicated that the hybridization reaction was completed after $25 \mathrm{~min}$. From a view of the sensitivity and assay time, $25 \mathrm{~min}$ was generally used for hybridization time.

3.3. Amplification of AuNPs. Could the application of the gold nanoparticles enhance the immobilization capacity of probe DNA and amplify signal of DNA hybridization? In this paper, we fabricated two different sensors: one is a sensor containing AuNPs, and another containing no AuNPs. The electrochemical investigation was performed as experiment Section 2.4, and the results were shown in Figure 4. It could be observed that the sensor containing AuNPs has a large signal (Figure 4(A): $10.16 \times 10^{-7} \mathrm{~A}$ ) compared with the sensor containing no AuNPs (Figure 4(B): $2.29 \times 10^{-7} \mathrm{~A}$ ). These results suggested that the immobilization capacity of probe DNA and hybridization signal improved greatly in the presence of AuNPs.

3.4. Selectivity of the DNA Biosensor. Differentiation of single mismatches is of significant interest for a variety of important applications. In this paper, the selectivity of the DNA biosensor was also evaluated by using single-base mismatch, no complementary and complementary DNA sequences. As is shown in Figure 5, it could be observed that the response of single-base mismatch sequence has a significant difference with that of complementary sequence. These results indicated that this DNA biosensor can distinguish single-base mismatch DNA sequence. 


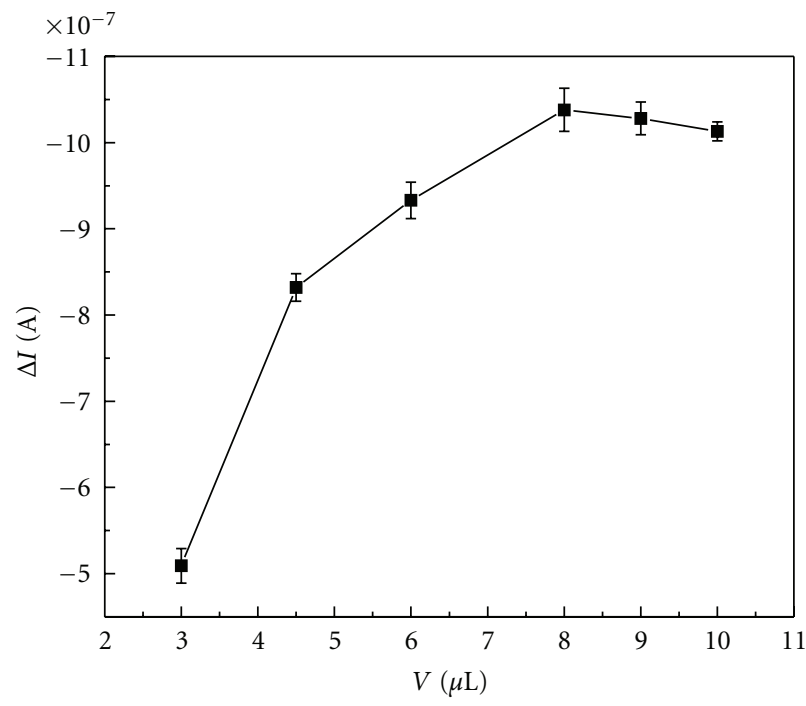

(a)

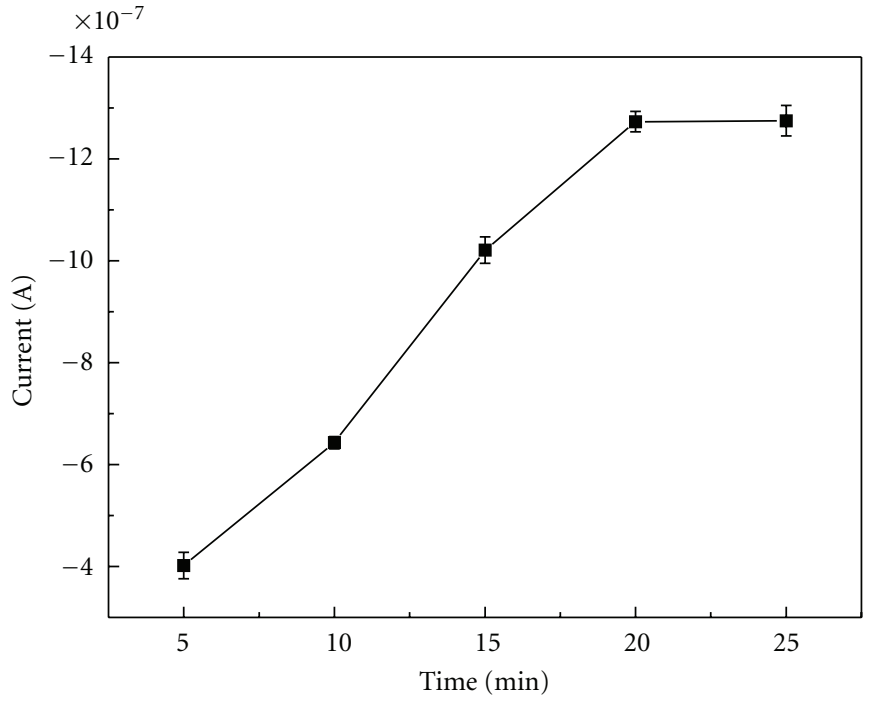

(b)

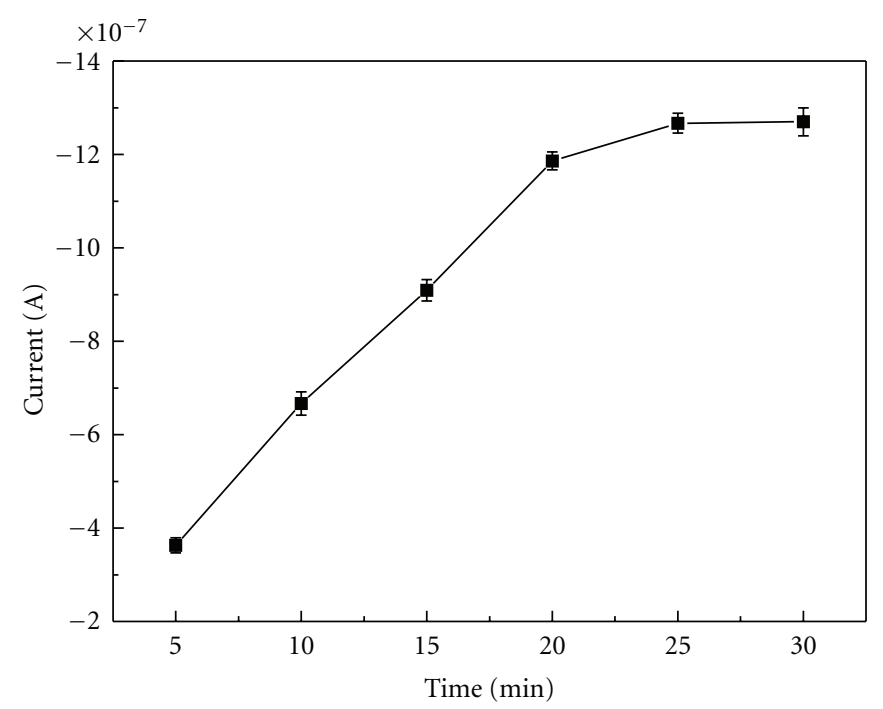

(c)

FIgure 3: (a) Peak current of adriamycin $(\Delta I)$ dependence of amounts of probe DNA. The concentration of complementary target DNA is $1.0 \times 10^{-10} \mathrm{M}$; DPV parameters were the same as in Figure 2(B). (b) Effect of accumulation time on the DPV signals of adriamycin. The concentration of adriamycin is $1.0 \times 10^{-6} \mathrm{M}$; DPV parameters were the same as in Figure 2(B). (c) DPV signals of adriamycin dependence on DNA hybridization time. The concentration of adriamycin is $1.0 \times 10^{-6} \mathrm{M}$; the concentration of complementary target DNA is $1.0 \times$ $10^{-10}$ M. DPV parameters were the same as in Figure 2(B).

3.5. Analytical Performance. Under the optimal conditions, the analytical performance of the DNA biosensor was investigated using the immobilized probe DNA to hybridize with the different concentrations of the complementary sequence. Figure 6 shows the DPVs records of intercalated adriamycin at various complementary oligonucleotides concentrations. It could be observed that the peak currents of adriamycin increased with increasing the concentration of complementary DNA, and the peak currents difference $(\Delta I)$ was linear with the logarithmic value of the concentration of the complementary DNA in the range from $5.0 \times 10^{-13}$ to $1.0 \times 10^{-9} \mathrm{M}$. The regression equation was $\Delta I\left(10^{-7} \mathrm{~A}\right)$ $=3.5518 \log C_{\mathrm{DNA}}+45.3301$ (unit of $C$ is $\mathrm{M}$ ), and the regression coefficient $(R)$ of the linear curve was 0.9979 . The detection limit is $1.7 \times 10^{-13} \mathrm{M}(\mathrm{S} / \mathrm{N}=3)$. Compared with reported sensors [23-25], this DNA biosensor showed higher sensitivity.

3.6. Reproducibility, Reusability, and Stability of the DNA Biosensor. The reproducibility of biosensor is a very important factor for their application. Four DNA sensors were fabricated independently under the same conditions and used to detect $1.0 \times 10^{-10} \mathrm{M}$ complementary DNA. And the reduction peak currents of adriamycin were $1.217 \times$ $10^{-6} \mathrm{~A}, 1.258 \times 10^{-6} \mathrm{~A}, 1.259 \times 10^{-6} \mathrm{~A}$, and $1.227 \times 10^{-6} \mathrm{~A}$, 


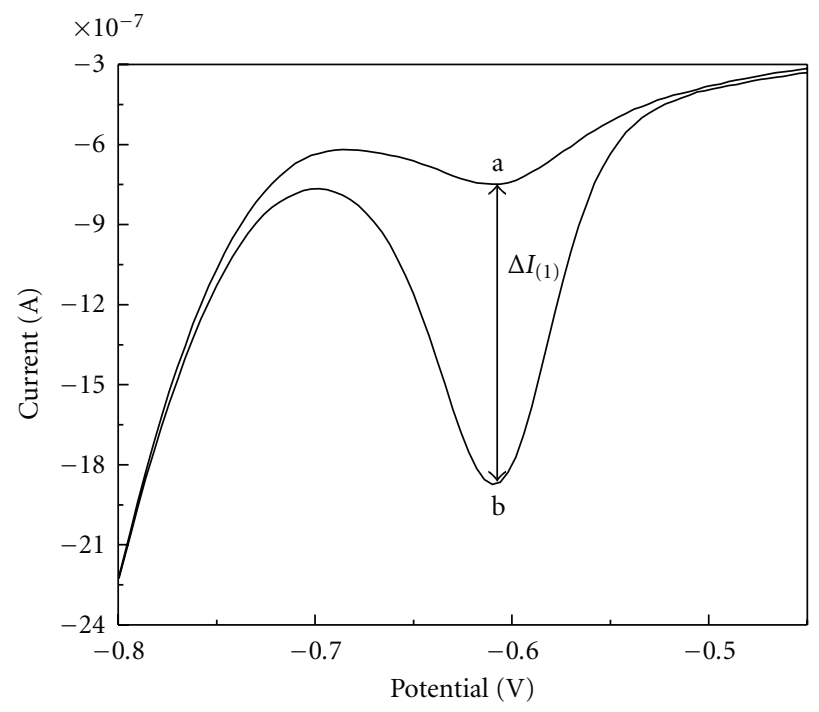

(A)

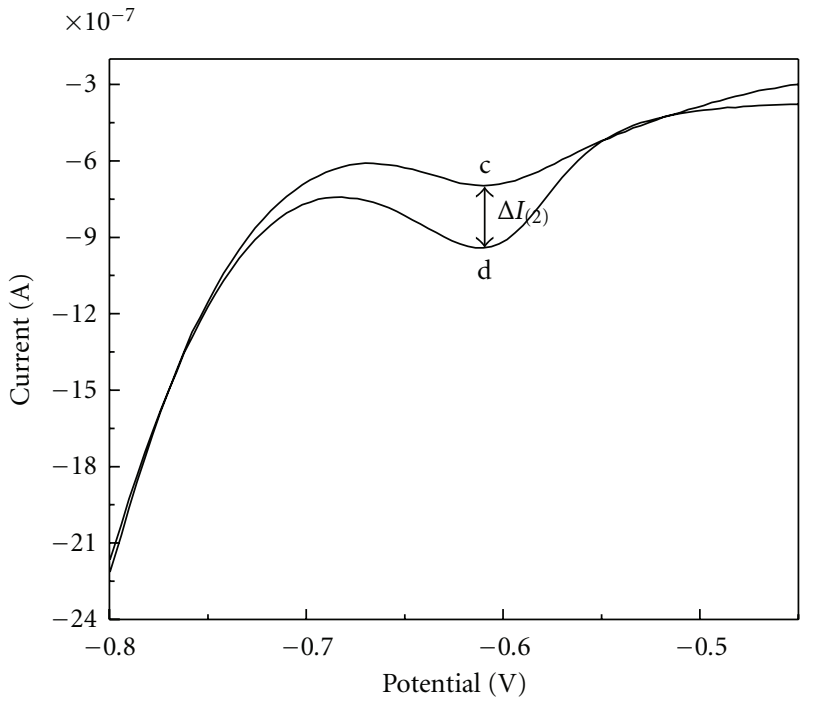

(B)

Figure 4: (A) DPV responses obtained for ss-DNA/MAA/AuNPs/Au (a), hybridized with $1.0 \times 10^{-10} \mathrm{M}$ complementary DNA (b). (B) DPV responses obtained for the ss-DNA/MAA/Au (c), hybridized with $1.0 \times 10^{-10} \mathrm{M}$ complementary DNA (d). Experiment condition: accumulation time of adriamycin: $20 \mathrm{~min}$; hybridization time: $25 \mathrm{~min}$. DPV parameters were the same as in Figure 2(B).

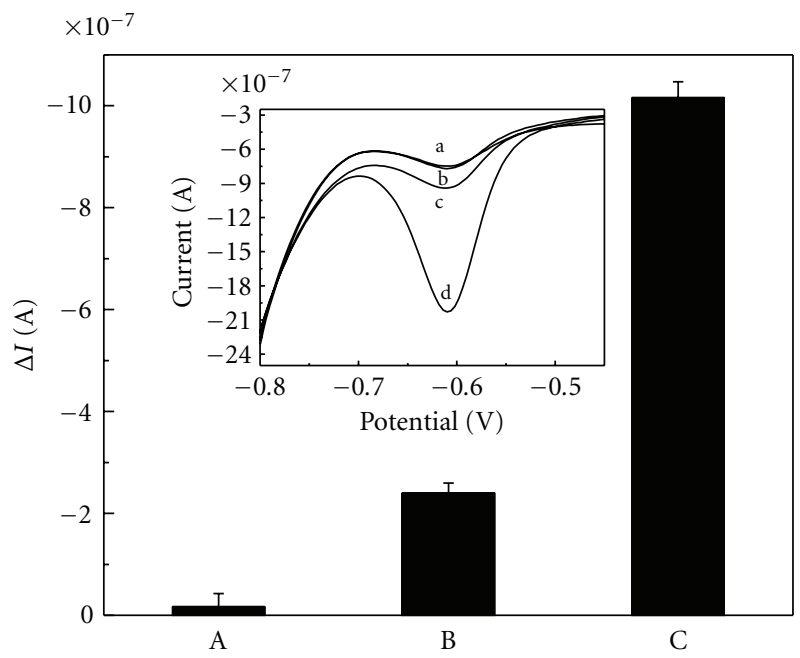

FIGURE 5: The histograms of the peak current difference $(\Delta I)$ of adriamycin versus different DNA sequences $\left(1.0 \times 10^{-10} \mathrm{M}\right)$ : $(\mathrm{A})$ noncomplementary sequence, (B) single-base mismatch sequence, (C) complementary sequence. Inset: DPV responses of adriamycin recorded at probe modified electrode (a) and after hybridization with $1.0 \times 10^{-10} \mathrm{M}$ noncomplementary sequence $(\mathrm{b}) ; 1.0 \times 10^{-10} \mathrm{M}$ single-base mismatch sequence (c); $1.0 \times 10^{-10} \mathrm{M}$ complementary sequence (d). Accumulation time of adriamycin: 20 min; Hybridization time: $25 \mathrm{~min}$. DPV parameters were the same as in Figure 2(B).

respectively. The average value was $1.2402 \times 10^{-6} \mathrm{~A}$, and the relative standard deviation (RSD) was $2.15 \%$.

The reusability of the DNA biosensor was investigated by immersing hybridized electrodes in hot water $\left(80^{\circ} \mathrm{C}\right)$ for 5-10 min to make ds-DNA into ss-DNA via thermal denaturation. The renew sensor was used to test $1.0 \times 10^{-10} \mathrm{M}$

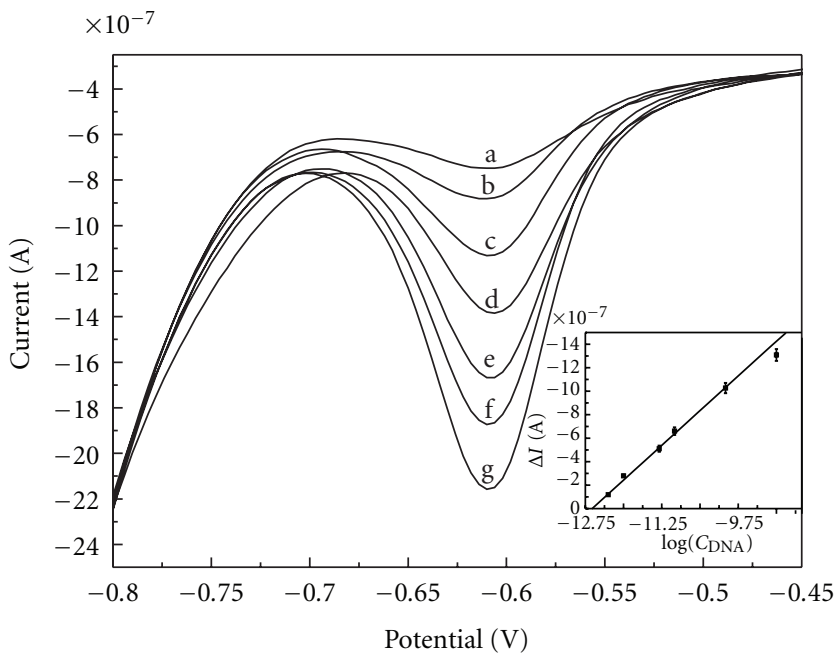

FIGURE 6: DPV response of the intercalated adriamycin recorded for the probe DNA modified electrode that hybridized with various concentrations of complementary DNA: (a) $0 \mathrm{M}$; (b) $5.0 \times 10^{-13} \mathrm{M}$; (c) $1.0 \times 10^{-12} \mathrm{M}$; (d) $5.0 \times 10^{-12} \mathrm{M}$; (e) $1.0 \times 10^{-11} \mathrm{M}$; (f) $1.0 \times 10^{-10} \mathrm{M}$; $(\mathrm{g}) 1.0 \times 10^{-9} \mathrm{M}$. Inset: Peak current $(\Delta I)$ of the intercalated adriamycin versus logarithm of concentration of complementary DNA. Error bars show the standard deviations of measurements taken from three independent experiments. Accumulation time of adriamycin: $20 \mathrm{~min}$; hybridization time: $25 \mathrm{~min}$. The DPV parameters were the same as in Figure 2(B).

complementary DNA and found that the fifth regenerated sensor has $84.7 \%$ response of the initial sensor (initial: 1.24 $\times 10^{-6} \mathrm{~A}$, final: $1.05 \times 10^{-6} \mathrm{~A}$ ). This result indicated the proposed DNA biosensor had a good reusability. 
The stability of the biosensor was also examined. The DNA sensor was stored in a freezer at $4^{\circ} \mathrm{C}$ for two weeks, and no apparent change about the peak current of adriamycin was observed.

\section{Conclusions}

A simple and sensitive electrochemical DNA biosensor based on ss-DNA/MAA/AuNPs modified electrode was fabricated. AuNPs could enhance the immobilization capacity of probe DNA and amplify electrochemical signal. This DNA biosensor exhibited excellent selectivity and stability.

\section{Acknowledgment}

The authors gratefully acknowledge the National Nature Science Foundation of China (no. 20675002), which financially supported this work.

\section{References}

[1] F. Patolsky, G. Zheng, and C. M. Lieber, "Nanowire sensors for medicine and the life sciences," Nanomedicine, vol. 1, no. 1, pp. 51-65, 2006.

[2] D. Ivnitski, D. J. O’Neil, A. Gattuso, R. Schlicht, M. Calidonna, and R. Fisher, "Nucleic acid approaches for detection and identification of biological warfare and infectious disease agents," BioTechniques, vol. 35, no. 4, pp. 862-869, 2003.

[3] F. Lucarelli, I. Palchetti, G. Marrazza, and M. Mascini, "Electrochemical DNA biosensor as a screening tool for the detection of toxicants in water and wastewater samples," Talanta, vol. 56, no. 5, pp. 949-957, 2002.

[4] V. Benoit, A. Steel, M. Torres, Y. Y. Yu, H. Yang, and J. Cooper, "Evaluation of three-dimensional microchannel glass biochips for multiplexed nucleic acid fluorescence hybridization assays," Analytical Chemistry, vol. 73, no. 11, pp. 24122420, 2001.

[5] R. Y. Wang, M. N. Ji, R. Wang, and J. Shi, "Stopped-flow kinetic fluorimetric studies of the interaction of $\mathrm{Ru}(\mathrm{II}) \mathrm{com}$ plex with DNA and its analytical application," Spectrochimica Acta Part A, vol. 71, no. 3, pp. 1042-1048, 2008.

[6] Q. Wang, X. Yang, and K. Wang, "Enhanced surface plasmon resonance for detection of DNA hybridization based on layerby-layer assembly films," Sensors and Actuators B, vol. 123, no. 1, pp. 227-232, 2007.

[7] X. Yang, Q. Wang, K. Wang, W. Tan, and H. Li, "Enhanced surface plasmon resonance with the modified catalytic growth of Au nanoparticles," Biosensors and Bioelectronics, vol. 22, no. 6, pp. 1106-1110, 2007.

[8] J. Zhang, R. Lao, S. Song, Z. Yan, and C. Fan, "Design of an oligonucleotide-incorporated nonfouling surface and its application in electrochemical DNA sensors for highly sensitive and sequence-specific detection of target DNA," Analytical Chemistry, vol. 80, no. 23, pp. 9029-9033, 2008.

[9] C. Ding, F. Zhao, M. Zhang, and S. Zhang, "Hybridization biosensor using 2,9-dimethyl-1,10-phenantroline cobalt as electrochemical indicator for detection of hepatitis B virus DNA," Bioelectrochemistry, vol. 72, no. 1, pp. 28-33, 2008.

[10] M. Li, S. Huang, P. Zhu, L. Kong, B. Peng, and H. Gao, "A novel DNA biosensor based on ssDNA/Cyt c/lCys/GNPs/Chits/GCE," Electrochimica Acta, vol. 54, no. 8, pp. 2284-2289, 2009.
[11] T. G. Drummond, M. G. Hill, and J. K. Barton, "Electrochemical DNA sensors," Nature Biotechnology, vol. 21, no. 10, pp. 1192-1199, 2003.

[12] J. Zhang, S. Song, L. Zhang et al., "Sequence-specific detection of femtomolar DNA via a chronocoulometric DNA sensor (CDS): effects of nanoparticle-mediated amplification and nanoscale control of DNA assembly at electrodes," Journal of the American Chemical Society, vol. 128, no. 26, pp. 8575-8580, 2006.

[13] H. Zhong, X. Lei, X. Hun, and S. Zhang, "Design of one-toone recognition triple Au nanoparticles DNA probe and its application in the electrochemical DNA biosensor," Chemical Communications, no. 45, pp. 6958-6960, 2009.

[14] S. Zhang, J. Xia, and X. Li, "Electrochemical biosensor for detection of adenosine based on structure-switching aptamer and amplification with reporter probe DNA modified Au nanoparticles," Analytical Chemistry, vol. 80, no. 22, pp. 83828388, 2008.

[15] J. Wang, J. Li, A. J. Baca et al., "Amplified voltammetric detection of DNA hybridization via oxidation of ferrocene caps on gold nanoparticle/streptavidin conjugates," Analytical Chemistry, vol. 75, no. 15, pp. 3941-3945, 2003.

[16] M. H. Abouzar, A. Poghossian, A. M. Pedraza et al., "An array of field-effect nanoplate SOI capacitors for (bio-)chemical sensing," Biosensors and Bioelectronics, vol. 26, no. 6, pp. 30233028, 2011.

[17] K. Zhang, H. Ma, L. Zhang, and Y. Zhang, "Fabrication of a sensitive impedance biosensor of DNA hybridization based on gold nanoparticles modified gold electrode," Electroanalysis, vol. 20, no. 19, pp. 2127-2133, 2008.

[18] H. Ma, L. Zhang, Y. Pan, K. Zhang, and Y. Zhang, "A novel electrochemical DNA biosensor fabricated with layer-by-layer covalent attachment of multiwalled carbon nanotubes and gold nanoparticles," Electroanalysis, vol. 20, no. 11, pp. 12201226, 2008.

[19] Y. Zhang, H. Ma, K. Zhang, S. Zhang, and J. Wang, "An improved DNA biosensor built by layer-by-layer covalent attachment of multi-walled carbon nanotubes and gold nanoparticles," Electrochimica Acta, vol. 54, no. 8, pp. 23852391, 2009.

[20] M. T. Castañeda, S. Alegret, and A. Merkoçi, "Electrochemical sensing of DNA using gold nanoparticles," Electroanalysis, vol. 19, no. 7-8, pp. 743-753, 2007.

[21] X. Zhang, F. Shi, X. Yu et al., "Polyelectrolyte multilayer as matrix for electrochemical deposition of gold clusters: toward super-hydrophobic surface," Journal of the American Chemical Society, vol. 126, no. 10, pp. 3064-3065, 2004.

[22] A. W. Peterson, R. J. Heaton, and R. M. Georgiadis, "The effect of surface probe density on DNA hybridization," Nucleic Acids Research, vol. 29, no. 24, pp. 5163-5168, 2001.

[23] S. F. Liu, Y. F. Li, J. R. Li, and L. Jiang, "Enhancement of DNA immobilization and hybridization on gold electrode modified by nanogold aggregates," Biosensors and Bioelectronics, vol. 21, no. 5, pp. 789-795, 2005.

[24] H. Cai, C. Xu, P. He, and Y. Fang, "Colloid Au-enhanced DNA immobilization for the electrochemical detection of sequencespecific DNA," Journal of Electroanalytical Chemistry, vol. 510, no. 1-2, pp. 78-85, 2001.

[25] J. Kang, X. Li, G. Wu, Z. Wang, and X. Lu, "A new scheme of hybridization based on the $\mathrm{Au}_{n a n o}$-DNA modified glassy carbon electrode," Analytical Biochemistry, vol. 364, no. 2, pp. 165-170, 2007. 


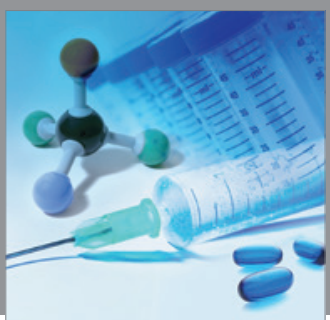

International Journal of

Medicinal Chemistry

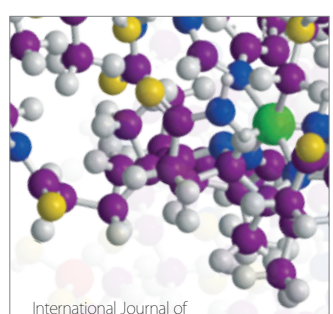

Carbohydrate Chemistry

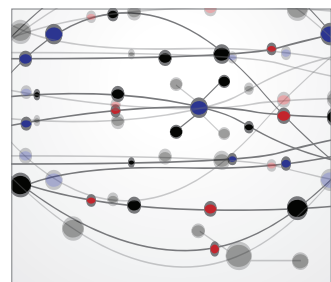

The Scientific World Journal
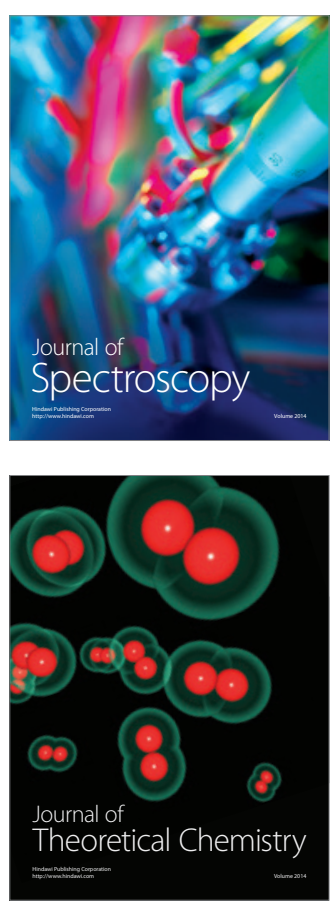
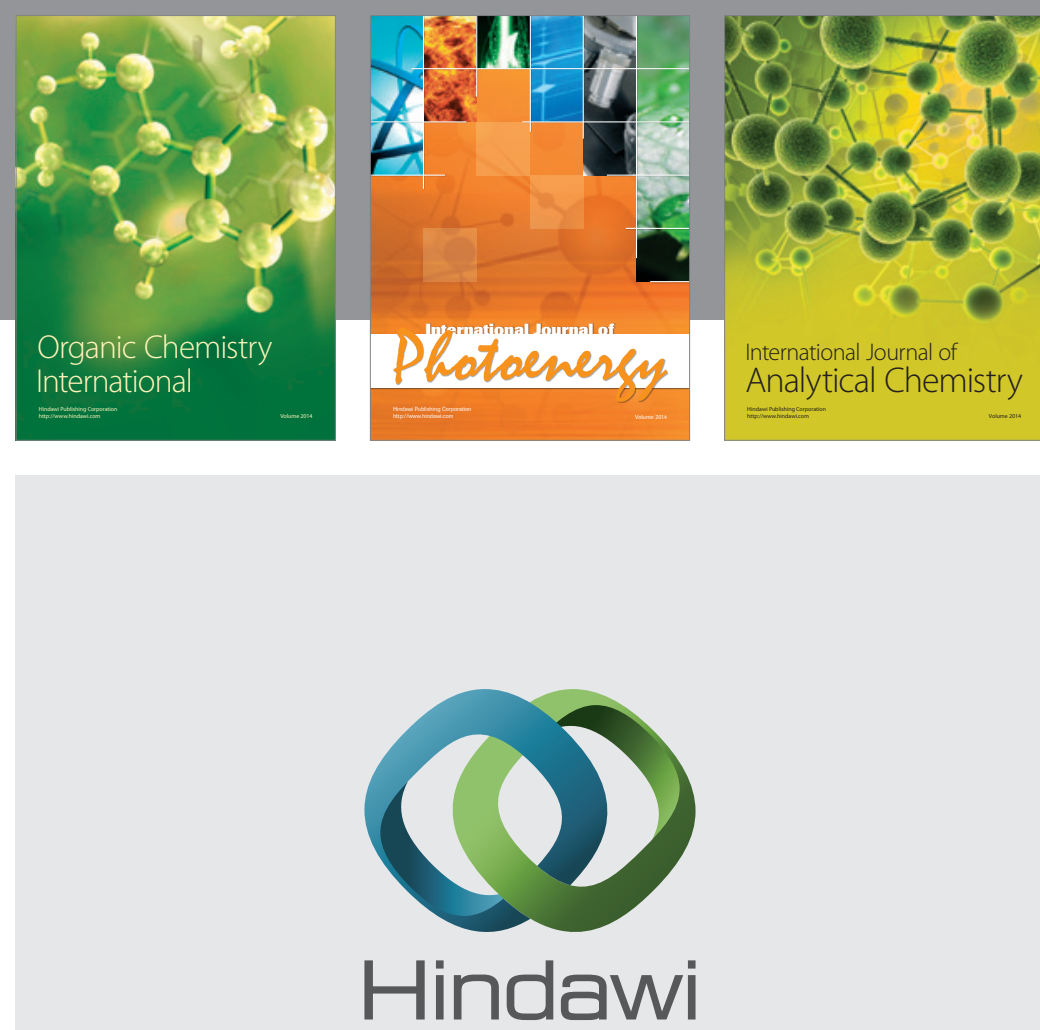

Submit your manuscripts at

http://www.hindawi.com
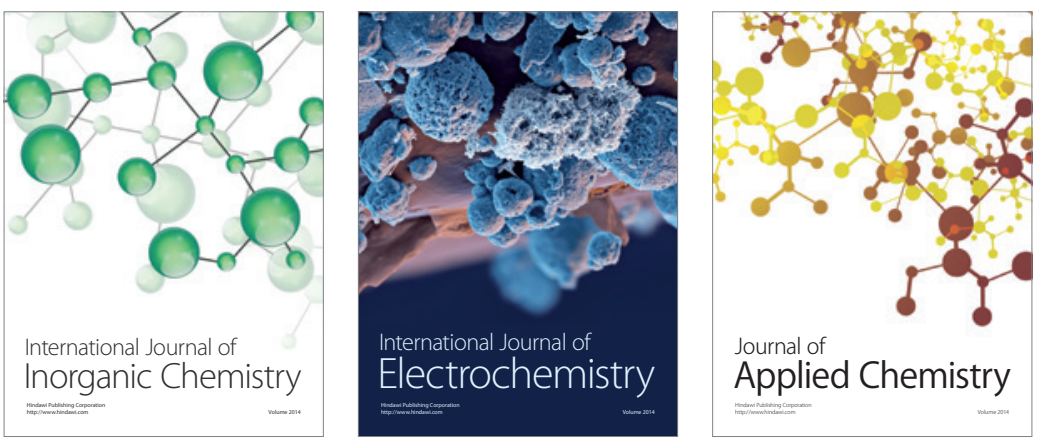

Journal of

Applied Chemistry
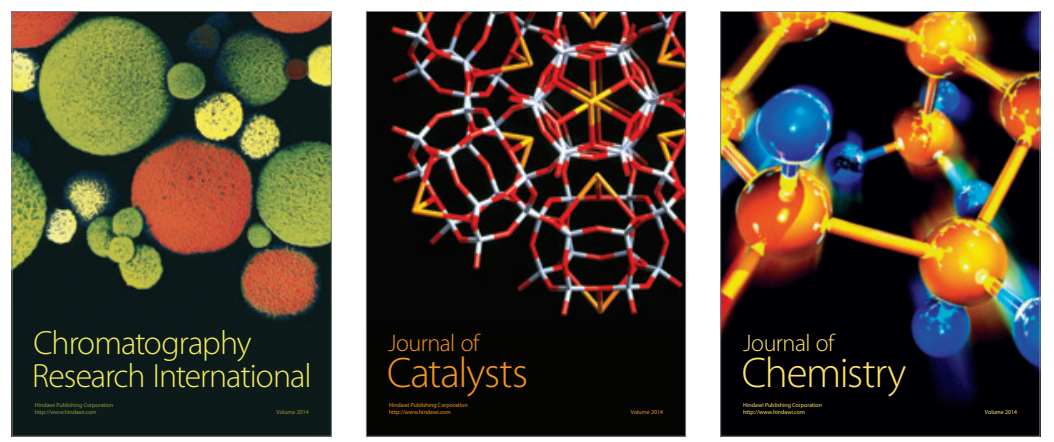
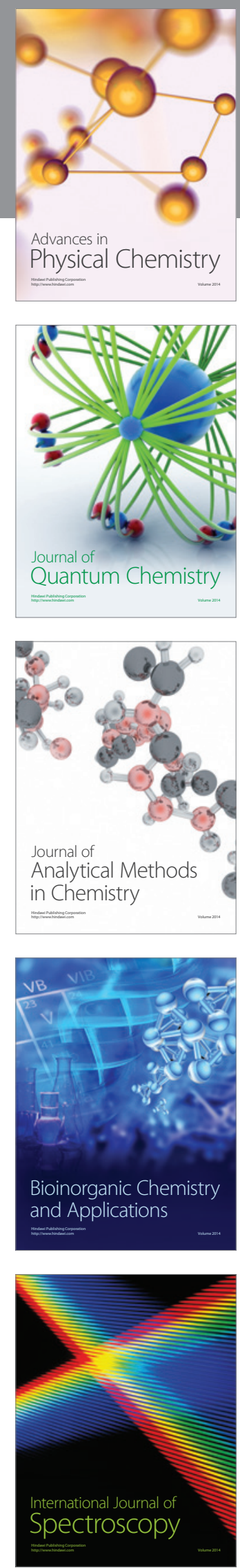